\title{
Obituary: Richard T. Johnson, M.D.
}

\author{
Avindra Nath ${ }^{1}$ \\ Received: 1 December 2015 / Accepted: 8 December 2015 /Published online: 4 January 2016 \\ (C) Journal of NeuroVirology, Inc. (outside the USA) 2016
}

On November 22, 2015, we lost the "Father of Neurovirology". However, Dr. Richard T. Johnson was more than that. He was a legend and an extraordinary person. He was brilliant, funny, adventurous, sincerely kind, engaged with so much of the world, and committed to making a difference, which he did in many realms. He was intensely curious, deeply thoughtful, and wise. The world lost a truly a great man who inspired the careers of many.

Dick's interest in the pathogenesis of viral diseases and viral infections of the central nervous system began in the 1960s when he was in the Department of Viral Diseases at Walter Reed Army Institute of Research. He worked with Dr. Edward Buescher, a virologist, and characterized the pathogenesis of enterovirus infections and the effects on the central nervous system. He went on to the Massachusetts General Hospital where he trained in neurology. Dick Johnson's first faculty position was in the Neurology Department at Case Western Reserve University School of Medicine (1964-1969). In 1969, he joined the faculty of the Johns Hopkins University as the Dwight D. Eisenhower Professor of Neurology, a position he held until his appointment as Neurologist-in-Chief and Director of the Department of Neurology in 1988. He held this position until 1997. Upon retirement, he took on the task as the Editor-in-Chief of the Annals of Neurology and served as the Director of the National Neuroscience Institute of Singapore, a position he held until 2000. In 2001, he

Avindra Nath

avindra.nath@nih.gov

1 Section of Infections of the Nervous System, National Institute of Neurological Disorders and Stroke, Building 10, Room 7C103, 10 Center Drive, Bethesda, MD 20892, USA

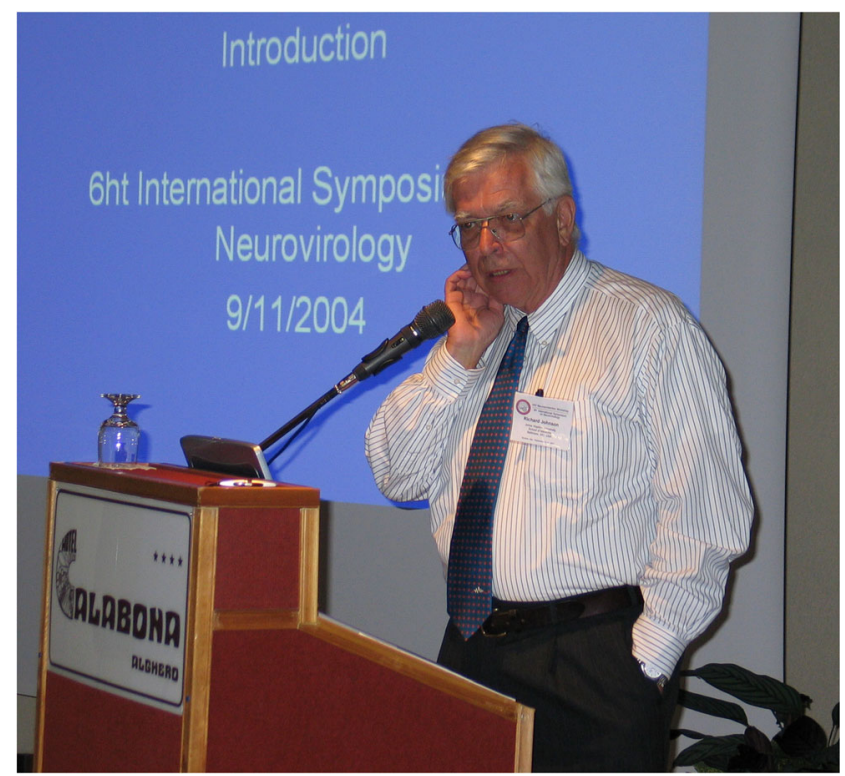

Dr. Johnson at the 6th International Symposium on NeuroVirology held in Sassari, Italy in September, 2004

became a Distinguished Service Professor of The Johns Hopkins University, a position he held until his death. Both his clinical and basic research work spanned nearly half a century and was focused on infections of the nervous system. Dick inspired the careers of many. One of his most important roles in these fields was the postgraduate training of M.D.'s, Ph.D.'s, and D.V.M.'s as leaders in biomedical research. Among the 40 or more fellows that he has trained, 14 became chairs of departments at major medical institutions (Clements 2000).

While working at the Walter Reed in the 1950s, Dick met D. Carleton Gajdusek, 1976 Nobel Prize winner for his work on transmissible spongiform 
encephalopathies (TSE). In 1964, Johnson himself observed a case of Kuru, in Papua New Guinea. When Dick was at Hopkins, he held joint lab meetings with Gajdusek's lab. He helped examine the first chimpanzee that developed signs of Kuru after Gajdusek experimentally inoculated it with brain extracts from a human victim. Dick served as a special consultant to the NIH on TSEs and chaired a US Institute of Medicine committee on TSEs. The committee released a report in 2004, stressing the need for expanded research into prion diseases (Hileman 2004).

In 1995, when the idea to establish the Journal of NeuroVirology was put forth by Kamel Khalili in Philadelphia, Dick was extremely supportive of this initiative. Dick penned the foreword included in the inaugural issue of the journal and his words from 20 years ago were indeed prescient:

Neurovirology now is recognized as a discipline with a growing cadre of investigators and a unique body of knowledge. It now has its own journal as a statement of that stature. It is also a field that has expanded rapidly and will continue to grow. Growth is assured by the nature of viruses with their explosive replication and high mutational rates and by the changes in society with burgeoning human populations and jet speed mobility that enhance the opportunities for viruses to evolve, to be maintained among humans, and to spread worldwide. New viruses and viral infections will emerge. HIV is unique only in scope; in recent years we have seen the appearance of California encephalitis in the mid-west, massive epidemics of hemorrhagic conjunctivitis with a polio-like syndrome throughout Africa and Asia, and the emergence of new arenaviruses with agricultural encroachment on rodent habitats. Within my 38 years in the field, I have seen scores of new viruses related to acute neurological diseases, and a new agent appear causing unprecedented numbers of infections with new syndromes and novel questions of pathogenesis. The evolution of neurovirology has been fast and fascinating; its future, to be chronicled in this journal, should prove even more exciting (Johnson 1995).

Three years later, when the first International Symposium on NeuroVirology was organized in Philadelphia, Dick delivered the opening lecture, which was well attended by prominent neurovirologists, where he highlighted the importance and evolution of the interdisciplinary field of neurovirology. He was very enthusiastic about the formation of the new society, the International Society for NeuroVirology (ISNV). Dick attended each and every meeting of the ISNV except for the most recent meeting due to his illness. He received the first Pioneer award from ISNV in 1992. At each meeting, the ISNV gives a student award in his name. At the ISNV meeting in 2013 in Washington, DC, Dick gave a talk on the history of the field of neurovirology. The following is an excerpt in Dick's own words of how he stumbled into the field of neurovirology that was written by him as a foreword for a book on clinical neurovirology edited by Joseph Berger and myself.

My long journey into what is now called neurovirology began on a winter night in San Francisco in 1957. The Medicine house staff from Stanford University Hospitals were having a party at the Chief Resident's house. In the kitchen Rod Beard, a young attending, lifted his drink and congratulated me for being selected as an assistant resident. At that time I wanted nothing more than to stay at Stanford and practice Internal Medicine in Pacific Heights. Sadly I informed him that I had just received my draft notice and would probably be leaving my wife in California and going to Korea. "You don't want to do that!" he said. I agreed. He asked why I did not do research in the Army - possibly in virology. I laughed. I had never done any research, and there was no field in which I knew less than in virology. "Then you would be bound to learn something," he chided. That off-the-cuff kitchen conversation changed my life.

Several weeks later, a telephone call came from Walter Reed Army Institute of Research (WRAIR) requesting a meeting in San Francisco the following week-at midnight in the bar of the St. Frances Hotel. The contact turned out to be Geoffry Edsall, head of the Communicable Diseases Division. He was waiting in the bar when I arrived. He asked if I would be interested in going to Southeast Asia to work on a pediatric service and send specimens from febrile patients back to WRAIR. He explained that "if we ever deployed troops in Southeast Asia" the military would need to know what infectious diseases might be encountered. Since we had only recently extracted ourselves from Korea, the French had recently lost Vietnam, and our leaders had spoken of the folly of fighting land wars in Asia, the idea seemed absurd. On the other hand, going to Southeast Asia with my wife and in civilian clothes was not an opportunity to pass up. I eagerly volunteered to become a virologist. I was posted to WRAIR but never assigned to Asia. I arrived at the peak chaos of the 1957 Asian influenza epidemic, and, when that settled, I concentrated on studies of central nervous system infections. Herpes simplex virus, arthropod-borne virus, and enterovirus infections of the nervous system were my primary concerns; viruses that continue to pose fascinating questions in epidemiology, pathogenesis, diagnosis, and treatment. During 
those years, I consulted with Webb Haymaker on the neuropathological changes in our human tissues and experimental animals. I often accompanied Des O'Doherty on Neurology rounds and Wallie Nauta at weekly neuroanatomy conferences. In those days the knowledge of virology by pathologists and clinicians was rudimentary, and the knowledge of the nervous system by microbiologists was negligible. That led me to choose the road less traveled; I opted to train in neurology and neuropathology.

After clinical training at the Massachusetts General Hospital, I wanted to return to experimental virology. Encouraged by Elizabeth Hartmann, the Director of Training Programs for the National Institutes of Neurological Diseases and Blindness, I applied for a special fellowship to work with Frank Fenner at the John Curtin School of Medical Research in Canberra, Australia. My clinical mentor, Raymond Adams, was required to sign my application; he initially balked. No one in neurology was interested in viruses-I would have no colleagues-I would be wasting a potentially successful career. The reaction was not unique. The next year when Donald Harter applied to do virology at the Rockefeller Institute, he received similar advice from his mentor at the Neurological Institute at Columbia, Houston Merritt. Don and I both persisted.

In 1961, I prepared my fellowship application, and under the space for field of study, I typed "Pathogenesis of virus infections of the nervous system" - seriously over the allotted 42 spaces. Betsy Hartmann "whited-out" my area of interest and typed in "neurovirology". I objected to the apparent neologism, and I recall her smile and statement. "We have neuroanatomy, neurophysiology, and neurochemistry — Why not neurovirology?" The term neurovirology is still not legitimized by inclusion in Dorland's Illustrated Medical Dictionary, but I assume it will be in the next edition. I hope they give credit to Betsy" (Johnson 2003).

Dick was truly a visionary. He quickly realized the importance of studying the infections of the brain very early in his career and pursued it with great vigor against all odds. Yet, he always gave credit to others.

In 1999, when Dick received the Pioneer award from the International Society of Neurovirology, Janice Clements wrote a piece for the Journal of Neurovirology in which she detailed his spectacular training record. Excerpts from that piece are detailed below.

Dick trained a large number of the leaders in the field of virus pathogenesis and viral immunology, this article will highlight his important role in training. He began his tradition of training in 1967 at Case Western Reserve in
Cleveland. His first fellow was Dr. Kenneth Johnson who worked on California encephalitis and virus induced hydrocephalus; who later became the Chair of Neurology at University of Maryland. After being recruited to Johns Hopkins University School of Medicine in 1969 by Dr. Guy McKhann, Dick assembled a group of faculty and fellows with expertise in immunology, pathology, virology, and ultrastructure. Other faculty in the group were Dr. Robert Herndon (neurologist and electron microscopist) and Dr. Leslie Weiner (past chair of the Department of Neurology, University of Southern California Medical School and later chair of Neurology at University of Maryland).

Even the very first group of Dick Johnson's fellows became leaders in virology and immunology. Henry MacFarland is the past Laboratory Chief of the Neuroimmunology Branch and the previous Clinical Director at the National Institute of Neurological Disorders and Stroke, the National Institutes of Health. Diane Griffin is renowned for her immunological studies on Sindbis virus and measles virus, and is the past Chair of the Department of Molecular Microbiology and Immunology at the Johns Hopkins University School of Public Health. Bill Narayan was a leader in lentivirus pathogenesis first with studies of visna virus and CAEV and then using the simian immunodeficiency virus- macaque system as a model of AIDS, he was Chair of Microbiology at the University of Kansas Medical School. Howard Lipton is at Northwestern University where he has established a dynamic research group studying Tyler's virus pathogenesis.

The next group of fellows that joined Dick in 1972 included Larry Becker, M.D. Professor and Chairman of the Department of Neuropathology at the University of Toronto School of Medicine, Ljiljana Kostovic, Professor of Anatomy, University of Zagreb Medical School, Jack Burks, M.D. former president of the Rocky Mountain Multiple Sclerosis Center and Professor of Neurology at the University of Colorado School of Medicine.

Janice Clements joined Dick Johnson's laboratory as a fellow in 1975. She is the current Associate Dean and the past Chair of the Department of Comparative Medicine at Johns Hopkins University. She once remarked, "One of my lasting memories of this time is gathering as a group in Dick's office every Monday morning at 8:30 AM to discuss our individual research projects. It was where I learned to think about virus pathogenesis and the experimental approaches used in animal model and in vitro systems. The lessons I learned in those meetings have provided me with the framework for molecular pathogenesis studies of lentiviruses. Each of Dick's fellows was given a great deal of his time and direction, this gave each of us an enormous start on the road to independent research."

Other fellows in the laboratory were Raymond Roos, John Greenlee, Mary Lou Oster-Granite, Maria Mazlo, Benjamin Brooks, and Burk Jubelt. Dick's depth and breadth of 
knowledge of neurovirology was immense. He recruited fellows with very different backgrounds and experience and was able to train each of the fellows in a different virus system. John Greenlee worked on papovaviruses using a hamster model to study the induction of tumors. Mary Lou OsterGranite also studied the papovaviruses characterizing ultrastructural changes caused by these viruses in cultured cells. Ben Brooks focused his research on a mouse retrovirus that caused infections and spongioform changes in the CNS. Burk Jubelt studied the pathogenesis and CNS involvement in mouse-adapted poliovirus. Janice worked with Dick and Bill Narayan on visna virus as a model for multiple sclerosis. One of the really amazing results of being mentored by Dick Johnson is that each of the fellows worked on a newly developed virus model and many of them continued to study those systems throughout their careers. Janice Clements remarked, "I remember many late night discussions at the tissue culture hood or during incubations with Ben Brooks about this time in Dick Johnson's lab and how we would look back on this time in the future. Ben always maintained that this was the "golden period" for us and the lab, in terms of the varied research that was being done, the faculty (Bill Narayan, Diane Griffin, Jerry Wolinsky, and Dick Johnson) who were part of the group and the fellows who were training together. Indeed I remember it as a critical time in my career development."

Dick Johnson trained over 40 fellows since 1969. While it would be impossible to note all of them particularly notable is the number of neurologists Dick trained: Micheline McCarthy, Patricia Coyle, Alan Seay, Gunther Schwendemann, Walter Royal III, Peter G.E. Kennedy, Alan Jackson, Thiravat Hemachudha, William Tyor, Martin Westarp, Dana Gabuzda, David Irani, John Corboy, Christopher Power, Stephen Wesselingh, and Justin McArthur.

With the advent of the AIDS epidemic, a new CNS disease emerged caused by HIV-1 infection. Dick Johnson was involved early on in the clinical evaluation of the disease and its outcome, in research efforts, and in training the leaders in the NeuroAIDS field. Howard Gendelman joined the research training program and worked closely with Dick and Bill Narayan on developing sensitive in situ hybridization techniques to examine replication of lentiviruses. Steve Wesselingh examined the role of cytokines in the CNS. William Tyor with Dick Johnson, Diane Griffin, and Richard Markham developed a SCID mouse model to study aspects of the CNS infection. Justin McArthur worked closely with Dick on the clinical aspects of HIV infection in the CNS and has taken over many of the leadership roles in NeuroAIDS at Johns Hopkins since Dick retired. He is now the Director of the Department of Neurology at Hopkins (Clements 2000).

Although I was never formally trained as a fellow by Dick, my career has been heavily influenced by him and he was a mentor throughout my academic career. My foray into neurovirology started in the laboratory of Jerry Wolinsky when Jerry had just moved to Houston from Hopkins where he had worked with Dick. I studied rubella virus and carried on the work that had been initiated by Jerry and Dick. Later, when Chris Power and I were on faculty at the University of Manitoba in Canada, Dick came as a visiting professor. He had just stepped down as chair of neurology at Hopkins and had started his tenure in Singapore. He came in the month of March during the bitter cold of about $-30^{\circ} \mathrm{C}$. He had insisted in coming in the winter since he had fond memories of his childhood in Colorado and wanted to go dog sledding. He flew straight from Singapore to Winnipeg and Chris, Dick, and I drove directly from the airport to Lake Winnipeg that was frozen solid. We quickly learned how to strap the huskies to the sled and with 13 dogs to each sled we had a lot of dog power. I recall Dick telling the dog trainer that since we had not done much dog sledding before, we would like to first go slow and then pick up speed. To which the trainer replied, "Oh no. At first the dogs have a lot of energy, so we will go very fast initially and then slow down." And that turned out to be true. We were on the sleds all day and this turned out to be a very memorable experience for all of us and it was a story he talked about often. Later, when I joined Johns Hopkins University in 2002 as the director of the newly created Division of Neuroimmunology and Neuroinfectious Diseases, we named the Division after him. During the last 13 years, I got to know him as a friend, a colleague and most importantly as a mentor. We shared many patients together, and he attended neuroimmunology rounds on a regular basis. $\mathrm{He}$ was an outstanding clinician. Patients adored him. There were some patients with multiple sclerosis that he had followed in his clinic for over 30 years. I recall that when I first joined Hopkins, I remarked that there were no nurses in the neurology clinic to bring patients to the examination room to which he replied, "The neurological examination begins as you greet the patient in the waiting room and watch them walk to the examination room." Having trained as a neurologist before the era of CT and MRI scans, he was an excellent diagnostician who took great pride in skills of clinical observation, the kinds of which are hard to find today. In recent years, when Dick first fell ill, he got himself admitted to the neurology service at Hopkins with me as the attending physician. Even in that role he maintained a sense of humor and taught us how to be the most gracious and grateful patient.

Dick Johnson's research has had an enormous impact on how viral infections are studied and has pioneered an entirely new area of research, virus infections of the nervous system. Clearly his research has had a major impact on academic medicine. In addition, Dick's mentoring of the next several generations of virologists, neurologists, immunologists and neurovirologists will carry these areas into 
the next millennium. One of Dick's major goals in setting up his laboratory at Johns Hopkins was to provide the setting to train fellows. It is clear that he was enormously successful in achieving that goal.

Dick published over 300 original articles and chapters and edited 16 books. He has also published a single authored volume on Viral Infections of the Nervous System (1982; 2nd edition 1998). He was Editor-in-Chief of Annals of Neurology (1997-2005), and Current Opinion in Neurology (1994-2000). He served on the editorial board of 22 journals over his career including Science (1980-83). Dick received numerous awards during his career. These include the following: the Arthur Weil Award, American Association of Neuropathologists (1967); Humboldt Prize (Senior U.S. Scientist Award), Alexander von Humboldt Foundation (1976); Weinstein-Goldenson Award, United Cerebral Palsy Associations (1979); Gordon Wilson Medal, American Clinical and Climatological Association (1980); Comendador, Order of Hipolito Unanue, Republic of Peru (awarded by the President of Peru in 1981); Silver and Gold Award, University of Colorado Medical Alumni Association (1983); Association of American Physicians (1984); Jean Martin Charcot Award, International Federation of M.S. Societies (1985); Smadel Medal, Infectious Disease Society of America (1986); Institute of Medicine (now called the National Academy of Medicine) of the National Academy of Sciences (1987); Honorary or Corresponding Member of Neurological Societies of Peru, Brazil, Australia, Philippines, England and Canada (1971-90); Victor and Clara Soriano Award and Lectureship, The World Federation of Neurology (1993); Florence Rene Sabin Award, The University of Colorado Health Sciences Center (1993); First annual Pioneer in NeuroVirology Award by the International Society for Neurovirology (1999); Fellow of the Royal College of
Physicians, London (2003); and Lifetime Achievement award, Neuroscience India (2005).

Throughout his career, Dick held many leadership positions in professional societies. He was the President of the Baltimore Neurological Society (1973-74), 2nd Vice President of the American Academy of Neurology (1975-77), Chair, Scientific Advisory Board, Amyotrophic Lateral Sclerosis Society (1975-81), President of the American Neurological Association (1986-87) and Chair of the Medical Advisory Board of the National Multiple Sclerosis Society (1985-90). He frequently chaired several key committees for the National Academy of Sciences and the Food and Drug Administration.

Dick was preceded in death by his first wife, Fran, and is survived by his second wife, Sylvia, and his children Carlton, Erica, Matthew, and Nathan; and his grandchildren Richard, Ledger, Laith, Shaina, and Hailey. Dick's passing away has left a huge hole in the fields of neurology and neurovirology that will never be filled. But the many pleasant memories that we have of him will be cherished forever.

\section{References}

Clements JE (2000) 1999 pioneer in neurovirology: Richard T Johnson, MD. J Neurovirol 6(1):3-5

Hileman, B. (2004). "Richard T. Johnson: Pioneer neuroscientist says major improvements are needed in U.S. prion research programs" Chemical and Engineering News, July 21, 2004

Johnson RT (1995) Neurovirology: evolution of a new discipline. J Neurovirol 1(1):2-4

Johnson, R.T. (2003). Forward. Clinical Neurovirology (pp. v-viii). (Eds: A. Nath and J.R. Berger). CRC Press, LLC. Excerpts reproduced with permission. 